\title{
Application of Big Data Technology in Insurance Innovation
}

\author{
Lili Zheng ${ }^{1, a, *}$ and Lijun Guo ${ }^{1, b}$ \\ ${ }^{I}$ School of Insurance, Central University of Finance and Economics, Beijing, China

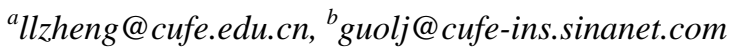 \\ *Corresponding author
}

\begin{abstract}
In 2015, China issued an action plan for promoting the development of big data showing that innovation in big data has become a necessary and inevitable choice for stabilizing growth, promoting reform, adjusting structures, benefiting people's livelihoods, and promoting the modernization of governance. A good policy environment and the rudimentary ecology of the big data industry create excellent developmental conditions for the development of big data in China. On the other hand, with the explosive growth of data resources and the rise of specialized big data enterprises, the application of big data has gradually changed from a theory to a reality. The insurance industry is in a period of technology-driven change globally. Digital technology represented by the Internet, mobile networks, social network, cloud computing, and big data increasingly influences the daily operation of the industry, and will usher in a golden development period in China's insurance industry.
\end{abstract}

Keywords: big data, insurance innovation, technology

\section{INTRODUCTION}

Big data refers to data sets whose size exceeds conventional database tools' ability to acquire, store, manage and analyze (According to McKinsey (2006)) information. The IDC believes that big data is a new generation of technology and information architecture (IT), which can extract value from large-scale and multi-category data through its high-speed collection, discovery, and analysis - as long as costs remain acceptable. Big data in a narrow sense refers to the extraction of valuable, massive, and diversified transaction data, interactive data, sensor data, etc. through its rapid acquisition, processing, and analysis. The data involved are so large that they cannot be collected, processed, or managed in a reasonable time frame by existing technology and tools. Therefore, they require a new processing mode, decision-making ability, insight and discovery ability, and process optimization ability.

The essence of big data is not simply a "large quantity" but through its application, a more "extensive," "deeper," and more "thorough" approach to data; and the ultimate goal when it comes to big data is to achieve quantitative and qualitative changes. Its application will lead to developments in predictive science, insurance principles, and actuarial technology from quantitative to qualitative changes, realizing the transformation from "why" to "what." The law of large numbers determines the data characteristics of insurance. The era of big data will transform people's understanding of data themselves. Going from data to "data particles" informs the process of social development, the driving force of science and technology, and social change, and also challenges traditional insurance theory and technology. From linear thinking to non-linear relationship decisions, the law of big data may be replaced by multi-dimensional law, so as to play a greater role in precision marketing, underwriting, and compensation, refined management, and insurance anti-fraud efforts.

\section{THE VALUE OF BIG DATA TO INSURANCE COMPANIES}

The application of big data brings great value to insurance companies.

Firstly, it improves the profit space of insurance companies and increases their premium income. Big data technology provides a strong guarantee for mastering effective customer demand in real-time, selecting high-quality customers, reducing loss ratios, and improving profits. Big data can partially solve information asymmetry, accurately classify customers according to their actual situations, enable companies to charge higher risk premiums for customers with higher risk levels, lower risk premiums for customers with lower risk levels, and encourage companies to retain high-quality customers as well as develop advantageous customer groups through customer behavior analysis, and improve the overall profitability of insurance companies.

Secondly, big data provides insurance companies with a greater market share. Big data can realize the precise marketing of products. The products can be accurately delivered to customers who need them through the analysis of user behavior. Relying on big data technology, insurance companies can efficiently search for customers from many different angles and various ways, finding potential new customers, tapping into the potential needs of existing customers, expanding traditional sales channels of insurance companies, and providing strong guarantees for an expanding market share.

Thirdly, the application of big data broadens the development space of insurance industry. Big data technology has broken through the boundary between the existing insurable risk and uninsured risk, changing original uninsured risk into insurable risk and expanding the scope of the insurance business, enabling customer resources to be shared among different business entities. BCG research found that cross-entity sharing of customer resources can tap into $10 \%$ to $20 \%$ of the potential market value, thus 
expanding the development space of the insurance industry.

\section{APPLICATION OF BIG DATA IN INSURANCE INNOVATION}

\subsection{Expands the Depth and Breadth of Insurance Product Innovation}

In traditional insurance product innovation it is easy to ignore the information derived from the behavior of individual consumers, so it is difficult to launch personalized products. Moreover, the data held by insurance companies are mainly internal data, but rarely contain external customer behavior data. Through big data, insurance companies can analyze user needs, reduce product development costs, solve the problem of product development cycle lengths being too long to keep up with consumer needs, and develop products more scientifically according to consumer behavior data. This can be done to achieve more interaction with customers, to provide products and services closer to customer needs, and to develop innovative, personalized products for consumers.

\subsubsection{Enables the Customization of Insurance Products}

Big data plays an important role in insurance product customization. In traditional insurance product design based on the original design concept, the insurance company can only design corresponding insurance products for groups that meet certain characteristics, which inevitably leads to an inconsistency between the product and customer's demands. Taking automobile insurance as an example, because of the difference of driver's background and driving habits, insurance types, and rates designed by insurance companies are different from actual ones. However, the traditional model can only adjust the premium by taking into account the number of accidents, which is essentially a post-correction mechanism.

The launch process of customized insurance is different from traditional insurance. Through the individual data of customers, such as their gender, social networks, health conditions, personalities, and other information, insurance companies make it possible to standardize the characteristics of insurance. For example, once vehicle digitization can be stored and shared on the Internet, with the help of big data processing, integration, and Internet analysis capabilities along with the data accumulated by customers such as driving age, occupation, driving habits, etc., the insurer can learn the customers' basic driving routes, the associated degrees of risk, driving habits, accident frequency, and other information, as well as evaluate customer risk and predict the possibility of future risk more accurately. For customers, the "private customization" of automobile insurance can be made possible.

There are some customized insurance products for a small group in China, such as absenteeism insurance launched by Ping An Property Insurance customized for taxi driver groups that use speeding drivers. When applying for compensation because of absenteeism, the taxi driver only needs to provide accident identification, a vehicle maintenance form, and an invoice (reflecting repair time and maintenance fees), or a medical invoice and rest certificate issued by a doctor, in order to apply for compensation from Ping An Property insurance. Compensation for absenteeism is a maximum of two days at a rate of 100 yuan per day for outpatients with a maximum of four days and 100 yuan per day for inpatients.

\subsubsection{Development of New Insurance Products}

Big data makes it possible to develop new insurance products. Some uninsurable risks caused by actuarial realities can be transformed into insurable risks in the era of big data. New insurance products like the protection of freight losses, the loss of cross-border transactions, and securing account funds like Alipay can be developed with big data. For example, Huatai return freight insurance is priced by analyzing massive amounts of seller and buyer transaction data, in which the recording, storage, and transmission of massive data are all dependent on advanced big data technology.

Network account security insurance is an innovation based on new insurable risks. "Choose to use the Internet or mobile client to pay" has almost become the most common method for every modern person with the rapid development of the e-commerce industry, but "online transactions" also cause personal account security problems such as network security loopholes, account theft, and swiping bank card fraud, and online banking account theft risk. Ping An has provided user capital transactions and guarantee insurance for its third-party payment platform since 2013. Ping An also designs fund security guarantees for the majority of e-commerce platforms and user virtual accounts.

Another example is weather index insurance. Weather insurance is a relatively mature business in the insurance market of developed countries, which is used in agriculture, industry, business, and people's lives, such as when an insurance company underwrites wind and precipitation in the production of wind power and hydropower; underwrites severe weather for the performance of large-scale outdoor events; and underwrites the cherry blossom period, rainy days, and so on for the travel of individual tourists. This kind of insurance can often be "exponential," that is, the meteorological parameters reach a pre-set standard corresponding to a degree of loss within a certain range. Zhongan Insurance Company designs small, high frequency, and fragmented weather index insurance products with the help of an Internet platform based on massive meteorological big data, and offers claim settlement automation.

\subsubsection{Creation of Product Bundling or Risk Management Service Packages}

It is possible to grasp the information of customers' preferences and insurance needs through big data analysis of existing customers to find out the best combination of insurance types to meet the immediate insurance needs of customers according to the model, or predict the insurance 
products needed in the customer's life cycle and bundle marketing. Companies, such as AXA, conduct in-depth explorations of individual customers' comprehensive demand for auto insurance and non-auto insurance. Based on the characteristics of the open platform of the Internet, the vast numbers of potential users are a good source of demand for the company. Insurance companies can also integrate the supply chain and establish an ecosystem based on the core insurance business through cooperation with other platforms, so that they become suppliers of a package of risk management services.

Many kinds AXA's online sales platforms balancing network auto insurance have accumulated a certain scale of auto insurance customer groups. Some customers purchase auto insurance products also have their non-auto insurance demands, such as travel insurance. The insurer explores the deep needs of end-customers, which can be conducive to the future development of products and transferring insurance content that cannot be realized by automobile insurance to non-automobile insurance, thus meeting customer demand to the greatest extent.

\subsection{Improvement of Insurance Product Pricing Accuracy}

Traditional actuarial science is based on the law of large numbers, through a certain sampling mode and technology; insurers extract a certain number of samples from a long-term, large number of business practices to build a mathematical model in order to price insurance products. However, the actual operational results are sometimes not satisfactory. On one hand, it is impossible to obtain enough samples, which leads to errors in pricing. On the other hand, insurance risk profiles change with time but insurance rates are fixed within a certain insurance period. Moreover, traditional actuarial pricing is based on the group rather than the individual, so it tends to abstract and generalize the individual in order to grasp the overall trend, which is totally different from the way in which big data emphasizes the individual's thinking.

Big data technology with the application of Internet of Things and in-time risk assessment technology, large-scale data can be collected to discover the laws behind the data, and make statistical results more accurate. Product pricing based on this is more in line with the actual situation. Big data greatly enriches insurance risk factors, such as living area, credit, income, browsing records, life work, and rest, exercise frequency, hobbies, online time, risk preference, genes, and other information. Multi-dimensional, comprehensive information will enrich the risk profile of a person, and combining individual data with the sample data of a group will promote the improvement of traditional actuarial theory and insurance pricing ability, as well as customer differentiation and personalization.

\subsubsection{Enrichment of Insurance Risk Factors}

Insurers can integrate the data obtained in multiple ways through big data technology and enrich their calculation of risk factors and pricing and their internal business platform data and accumulate data from Internet through various channels, such as SMS, e-mail, WeChat, microblog, apps, websites, etc. Through these data, risk factors can be defined in many respects. China Insurance Information Technology Management Co., Ltd. was established in 2014(now is China Banking and Insurance Information Technology Management Co., Ltd.), and is the first technology data company for insurance industry in China. It provides support for the exchange of information between insurance companies and between the insurance industry and other industries.

Big data is enriching automobile insurance risk factors as reflected in UBI (usage-based insurance). Insurance companies usually relied on department of motor vehicle driving records in order to determine insurance pricing and coverage before UBI. Insurance companies can learn how their customers drive and how their customers drive with UBI. UBI provides insurers with a more accurate picture of customer driving behavior. With UBI, sensor technology or small-scale digital equipment is inserted into the on-board diagnosis port (OBD) of the car so the system can collect different data such as acceleration, braking, and turning. When the data is wirelessly transmitted to the insurance company it can analyze potential risks within a certain time period and price them, thus determining a personalized premium and providing personal insurance services.

\subsubsection{Achievement of Accurate Pricing}

Traditional actuarial science is based on the historical loss data of sample types. Insurance companies can price life insurance according to life table data, combined with interest rates, premium rates, and other information. Insurance companies can price non-life insurance according to loss models based on historical loss data. Therefore, traditional actuarial pricing is based on a certain group or class of homogeneous samples. The insurance products based on big data essentially change the basis of actuarial pricing. Big data technology can make possible the individualized actuarial pricing of insurance products, and enable insurance companies to obtain an individual's risk information so as to determine an individual's personal insurance rate. With the development of big data technology, a more accurate and detailed life table can be constructed, and the calculation of loss risk probability and loss degree can also be more accurate.

Taking life insurance as an example, the life table is a summary table composed of the mortality rates at each age, which is compiled based on death statistics of various ages in a certain past time period. A life table is a record of past experiences and is often used to predict future events that are exactly the same in the future as in the past. Generally, age and gender are most often considered when designing a life table, but there are many other factors that affect mortality, including occupation, habits, past medical history, income, and so on. Big data can improve the ability to calculate the probability of death, and make more accurate premium prices, by the use of wearable devices to collect individual information, monitor human health in real time, including the amount of exercise, sleep, heartbeat, and other data. 


\subsubsection{Realization of Dynamic Premium Adjustments}

The general premium rate is fixed within the insurance period in traditional insurance company operation, but this means that the potential risk has not been identified, because the risk situation of the insured is constantly changing. Insurance products based on big data can adjust premium rates according to the real-time risk information changes of insurance objects.

"Step-by-Step Insurance," launched by Zhongan Insurance Company in 2015, is the first health management insurance product in China that integrated wearable devices and sports-related big data. Insurance customers join a health program by wearing a smart bracelet. The intelligent bracelet automatically records the user's movements and recommends major disease insurance with different coverage plans, including RBM 200,000, 150,000, and 100,000. It recommends the 100,000 yuan coverage plan when the 5,000 steps during the first 30 days; the 150,000 yuan coverage plan when customer average reaches 10,000 steps. The more the insured's historical step average increases, the higher the amount of coverage. When the steps exceed a certain value, the insured is awarded a deduction from the premium. The maximum deductible amount for the insured is 200,000 yuan. If the customer's daily steps reach a certain goal, the insured can get a partial premium reduction or even earn a $100 \%$ premium reduction or free premium. In this way, buy encouraging the insured's daily exercise, the next month's premium will be automatically adjusted, and the insurance service based on the movement factor as the actual pricing basis will realize a real-time adjustment of the premium.

\subsection{Realization of Precise and Differentiated Marketing}

Products and customers are closely related to the collection and analysis of big data in marketing the insurance industry. Big data can achieve a comprehensive picture of customers, help accurately obtain new customers and stock customers, realize the conversion of quasi-customers, and effectively prevent the loss of customers.

\subsubsection{Provides Insight into Customers}

Customer insight, or consumer insight, is the interpretation of trends in human behavior that aim to increase the effectiveness of a consumer product or service, as well as increase sales for the financial benefit of those providing the product or service. Most customers are now online and leave a trail of data on social media sites and search engines. This data provides valuable customer insights that brands should be analyzing. Big data, along with increasingly sophisticated analytical tools, has provided a wealth of information on customer behavior and attitudes.

Insurance companies can get a customer's personal attributes and information and establish customer categories, so as to understand customers' real and specific needs more quickly and deeply. Through the customer portrait created by big data, it is found that the post-80s have gradually played a larger role in society and family. When they enter the peak period of life, they need to take on work and family responsibilities, so their willingness to buy insurance will be stronger. The proportion of post-90s' customers is the fastest growing group.

\subsubsection{Enables the Accurate Acquisition of New Customers}

Insurance companies can carry out multi-dimensional and three-dimensional analyses of customers through the comprehensive utilization of internal and external data, not only to understand customers' consumption habits and consumption abilities, but also to understand customers' insurance preferences and channel preferences, and accurately understand customers' recent needs, identify potential customers, and make limited choices for prospective customers. In addition, corresponding sales channels can be configured according to customers' consumption habits and the characteristics of each channel, and marketing channels can be selected accurately to contact these customers.

The customization of products can be realized through the precise positioning of users. Insurance companies carry out user stratification for the mobile network platforms of insurance products and develop new products for specific customers. For example, The People's Insurance Company (Group) of China Limited developed a liability insurance product especially for naughty children. It mainly protects the guardian's liability, insures the third party's personal injury or property loss caused by the guardian's negligence under the age of 18, and then provides protection for the guardian's economic loss.

\subsubsection{Promotes the Transformation of Prospective Customers}

Although many insurance companies have large customer bases, the vast majority of them are "quasi-customers," that is, very short-term insurance customers or customers who are given free insurance. Research shows that the conversion cost of prospective customers is far lower than the cost of acquiring new customers. However, due to the lack of information about potential customers and the limited means of analysis, for example, the contact information of short-term customers is controlled by the channel, making it impossible to sell them long-term insurance, leading to insufficient attention being paid to the transformation of targeted customers. Big data technology can track the behavior of potential customers, build prediction models based on external data, and quickly verify and adjust them, and then launch personalized marketing methods to show the products that these customers would be "most likely to buy." Insurance companies can also make more reasonable analyses according to customers' health, finance, credit, and other conditions so as to improve marketing efficiency and effectiveness. 


\subsubsection{Encourages the Precision Marketing of Stock Customers}

Stock customers refer to customers who have purchased insurance products. Big data can help to segment the existing customers of insurance companies, accurately understand their key needs, carry out additional insurance and cross sales, maximize customer value, and promote business collaboration. Insurance companies can provide customers with overall insurance services so as to effectively improve customer interest in one insurance company, because the more insurance products customers buy from the same insurance company, the higher cost of subsequently changing to another insurance company.

Sharing between insurance companies and other platforms makes cross-selling easier. Insurance companies can understand the Internet behavior preferences of existing customers with the help of the data platform, and thus provide targeted and precise marketing. For example, if customers pay more attention to maternal and infant products, they can recommend children's health insurance to such customers; if customers have good asset levels and often pay attention to financial media, they can recommend universal life insurance. Insurance companies can also build predictive response models based on massive data, mining out variables that effectively identify the insurance needs of customers, and then use real customer data to test their analysis by using these variables to screen customers.

\subsubsection{Prevents Customer Churn}

In the actuarial business, insurance companies do not pay enough attention to prevent customer churn, or the constant changing of customers. Big data has a significant effect on the recovery of lost customers and the establishment of early warning systems for imminent customer churns. Insurance companies can use big data to identify which customers they are most likely to lose, as well as when and why they will lose them, by means of predictive analysis. They can use this information to increase customer satisfaction and customer loyalty.

Big data technology can build a prediction model based on massive big data mining, which can effectively identify the characteristics of lost customers, to carry out early warning systems for cancellations, or recover lost customers by repairing customer relationships (such as an orphan list, a renewal list for lost customers, or a list of customers from external channels). Big data technology can help insurance companies to model the key information affecting the renewal rate according to various types of data such as policy type, insurance type, sales information, personnel information, economic ability, health status, etc., to screen out key factors affecting the customer's cancellation of their policies, and adjust the business accordingly. Big data technology can also help insurance companies to use regression algorithms to establish a continuous income risk prediction model or public opinion monitoring, classify existing customers according to their potential cancellation rate, locate the customers that may be lost, find the reasons for customer dissatisfaction, improve customer satisfaction, and recover relationships with these customers.

\subsection{Improves the Quality and Efficiency of Insurance Services}

Insurance companies can use big data to analyze and predict customer needs, provide customers with exquisite services, simplify service processes, improve service efficiency, provide personalized services, and provide value-added services, so as to effectively improve service levels and customer satisfaction.

\subsubsection{Improves the Quality of Insurance Services}

Insurance companies can use big data to analyze customers' characteristics, habits, and preferences to effectively improve service quality. For example, the "PICC" app, an important sales and service platform, provides customers with an insurance solution integrating insurance sales and services. PICC Property Insurance starts their promotion of this "product + app" on the mobile Internet, and optimizes the app. The PICC plan continuously conducts exclusive mobile promotion activities by integrating all kinds of internal and external resources, constantly mobilizing the enthusiasm of existing app users, and promoting purchase transformation through "double interest attraction." PICC also pushes products in combination with the consumption environment, strengthening the cognition and purchase of products on mobile terminals with scenario marketing, and promoting a surge of visits. PICC formulates key optimization schemes for the market, implements app download guidance for key application markets, and realizes external recognition and exposure for the "China People's Insurance client" app, and finally achieves sales growth.

\subsubsection{Simplifies the Service Process}

Big data simplifies the underwriting service process and brings great convenience to insurers and policyholders. In the era of big data, through cooperation with a variety of social platforms, insurance companies can obtain customer information including basic personal information, medical records, and driving records, and then provide targeted insurance products and quotations for customers. Ping An Property Insurance introduces direct sale auto insurance, both the renewal of old policies and new policies, which can be purchased by a one-click operation on WeChat, greatly improving the convenience of obtaining auto insurance. Customers can have more payment options when they buy insurance from WeChat, such as PICC, which simplifies the online auto insurance process from five steps to three steps, and adds convenient service functions such as the fuzzy matching of license plates.

Big data also brings convenience to insurance claims service. Insurance companies can use relevant data to establish an intelligent network claims platform, strengthen the connection with mobile Internet terminal applications, realize the automation of Internet insurance business processes, and greatly shorten the processing time of claims settlement. For example, flight delay insurance based on big data effectively simplifies the complicated process from purchase to claim settlement with customers through an information sharing mechanism directly connected with the 
third-party system.

\subsubsection{Improves Service Efficiency}

Big data improves the efficiency of insurance services, enables the optimization of customer data documents and their processing, optimizes automatic underwriting rules and web page processes, so as to reduce the amount of required customer input data, and improves the efficiency of document entry and underwriting.

Taking UBI insurance as an example, when accidents occur, the intelligent OBD recorder can take three photos and a short video at the moment of collision and upload them to the cloud, thereby enabling the insurance company to analyze the photos and videos, contact and verify the customer, and guide them to take photos of their loss-related car parts. The background can further analyze the photos taken by customers and verify the loss. For some complex cases that must be handled by professionals, big data technology may optimize the offline investigation process. When there is an event that needs to be handled by professional personnel, the background data in the cloud of the insurance company will send the accident-related information to the nearest survey vehicle from the accident site, and the professional personnel will then connect with the vehicle and communicate with the customer.

Another example is the establishment of automatic claim settlements of flight delay insurance using big data. The insurance company cooperates with a third-party aviation data provider through the integration of the two systems. Flight delay data can be obtained within a short time when the aircraft lands, triggering an automatic claim settlement, and paying the customer claim. This process not only eliminates the process of the customer collecting materials, but also eliminates the process of claim settlement review by the insurance company, so as to realize a fully automatic, paperless claim settlement process that brings the greatest convenience to customers.

\subsubsection{Provides Personalized Services}

Insurance companies can use big data to describe customers' personality, subdivide customers according to their purchasing habits, service preferences, and other information, and better carry out personalized services. For example, Ping An Property Insurance designed a "customer-centric" integrated service mode and built a one-stop customer online center, created independent service links such as purchase tracking, service queries, marketing, personal information maintenance, and successfully built a data retrieval and resources system. Through the "personal center," online customers can self-service purchases, track policies (including orders, policy status changes, distribution statuses, product evaluations), make queries, and input and modify personal information (including preferences, vehicles, distribution, common insurer information, etc.). The personal center also embeds auxiliary website functions such as recommending friends, providing subscription information, making complaints, and links to online customer service. In addition, with the help of the integrated service mode, Ping An has successfully created an underwriting claim settlement query for the company's channel customers and expanded self-service functionality, effectively compensating for defects and inconveniences in offline customer service, thus greatly improving service efficiency and customer satisfaction.

\subsubsection{Provides Value-added Services}

Big data technology can also provide value-added services for customers. Big data can realize the integration of insurance service resources, cross-border service efficiencies in product services and entertainment services, and directly penetrate the consumer lifestyle through fragmentation. For example, value-added services for vehicle insurance would be traffic information and vehicle maintenance records, which not only meet the needs of consumers, but also reduce their risk of car accidents. Another example is that Ping An Property Insurance launched the "good car owner" app, which can carry out the functions of making car insurance quotations, purchases, one-key case reports, and claim settlements, as well as inquiries to handle violations. In the "good car owner" app, the insured only need to input some basic information and then they can apply for insurance conveniently and quickly. After the insurance application is completed, they can associate personal information with their policy, and then look up my car, my insurance policy, and other relevant information, including agent violations and violation messages. China Life Property \& Casualty Insurance Company provides partners with accurate information of regional service providers, combines regional characteristics with customer location and facilitates customers to select service providers nearby with location-based services (LBS) and Social Network Services (SNS).

\subsection{Improves Risk Control and Anti-fraud Efforts}

Big data plays a significant role in risk control and anti-fraud efforts. Big data greatly improves the level of risk control, and enables the control of potential risks. It can also decrease asymmetric information, such as finding the relevancy between different data through risk scenario technology, intelligent systems, and biometric identification technology to track and identify fraud, help to establish anti-fraud networks, enable the identification of fraud, and prevent and mitigate the number of claims.

\subsubsection{Improves Risk Control}

The development of big data has greatly improved risk control in insurance companies. Insurance companies can obtain comprehensive information about the insured, and further obtain accurate risk information on customers. Big data technology can also improve the risk control level of potential risks when underwriting customers, and help to identify potential risks in advance to prevent potential risks from evolving into actual risks. Big data technology can connect the information compiled by insurance companies, banks, public security systems, hospitals, and other 
institutions to establish databases that identify "high-risk customers," "high-risk practitioners," "special lists," etc., then discover and identify high risk in real time and improve the efficiency of information transmission.

Risk control is a worldwide problem in health insurance. Supply induction, excessive demand, and insurance fraud hinder the development of health insurance. Insurance companies have curbed a large number of excessive medical behaviors and strictly controlled medical expenses by establishing their own medical networks. Some companies began to test the risk control mode of "insurance + medical treatment" by big data technology. The medical information platforms cover a large number of insured and successfully operate in the medical insurance and some hospitals in some cities in China. Insurance companies can collect medical information on patients, establish complete health information files on the insured, and prevent patients in advance and reimburse them after the disease, so as to better carry out risk control through cooperation with medical information platforms.

The "Personal Insurance Underwriting and Claims Risk Screening Platform," established in 2016, was initiated by the China Insurance Industry Association and supported by the Munich Reinsurance Company. This platform can realize risk information releases, if an insurance company finds a suspicious customer, the company will audit and manage through the "case release" function of the platform. The platform also has a function of risk information reply and query, which can record the information of suspected fraudulent customers by marking the risk information reply of other insurance companies. The platform also provides statistical analysis functions, which can analyze the data of fraud types and characteristics of fraudulent customers, monitor the development trends of fraud, and effectively identify underwriting and claims risks.

\subsubsection{Controls Potential Risks}

Insurance companies can strengthen customer behavior management by "tracking" customer behavior, reducing the probability of accidents of the insured, and reducing the risk of insurance companies by applying big data technology. Taikang Life Insurance Company online and Gudong (sports big data and service platform) launched the interactive insurance service called the "vitality plan." Gudong encouraged the insured to record and upload the data of each movement to the network and share the data and experience of their own movements. The insured who do exercise often will get additional benefits, such as premium discounts and gift feedback. Another example is Small Umbrella Insurance, an insurance company that encourages customers to exercise and reduce their health risks. Small Umbrella Insurance customers link public WeChat account "WeChat sports," pay the minimum daily insurance of one yuan, then according to the number of steps walked each day determine their daily bonus, which is between 0.2 and 1.6 yuan.

There are similar attempts in motor insurance. In UBI vehicle insurance, the insurance company analyzes the risks of customers through collected data. If it shows that the safe driving habits of customers have been formed and the probability of accidents has been reduced, the insurance company will take the initiative to reduce premiums. The application of smart home technology in home property insurance also reflects potential risk control using big data technology. The Internet of Things and in-time risk assessment technology, large-scale data can be collected to discover this used in residential insurance, when customers purchase home property insurance, they can obtain devices such as smoke detectors and sensors to remotely monitor their residence.

\subsubsection{Builds an Anti-fraud Network}

Big data technology integrates all departments, third-party platforms, networks, and communication operators of insurance companies by building an anti-fraud network, which can decrease asymmetric information and reduce insurance fraud. The insurance company can obtain the customer's purchase information and claim information in real time through the anti-fraud network, use big data analysis technology to assess the customer's credit level, and refuse to underwrite customers who may commit fraud; according to the customer's purchase information, insurance companies can also confirm whether the customer purchases excess insurance or duplicate insurance to avoid the high price of insurance. Secondly, the insurance company can obtain the customer's real-time accident information through the anti-fraud network. For example, when traffic police obtain accident report information, the insurance company can also know about it immediately. Insurance companies can obtain the data regarding the repair and maintenance of the insured's car in real-time through the network from the repair industry system, so as to avoid improper customers benefits from insurance payouts thus enabling the prevention of insurance fraud.

Anti-fraud networks can also use risk scenario technology in a very effective way. Risk scenario technology refers to the use of data to comprehensively to analyze the main means or characteristics of fraud cases. For example, in the field of vehicle insurance, when records show that "the same vehicle as a 'third party vehicle' has appeared many times" with "no one is injured," and "with the same damaged vehicle parts" and other accident features, the insurance company can discern that it may be a fraud event and make further investigation. The emergence of big data enriches the risk factors that can be read in scenarios, and greatly improve the recognition rate and accuracy rate of fraud events.

Both rule analysis and model analysis can analyze various scenarios and factors to generate risk cases. Rule analysis is summarizing the specific characteristics of a scene accumulated by operators in the inspection and claims settlement, and quantifying all its characteristics, then screening out the cases that meet the characteristics in the background system and further analyzing whether there is fraud. In model analysis, the data reflecting the risk of the claim case is deeply mined and processed into effective data that can be identified by the model. Then, the model is used to analyze and identify any claim cases with abnormal data levels.

The use of intelligent systems can also effectively identify fraud. For example, in UBI insurance, the intelligent OBD recorder can judge the authenticity of the accident through the video and photos taken at the time of collision. There is also the use of biometric technology. Biometric 
identification technology is a kind of technology that can identify or verify a human's unique biometrics. Due to its good discrimination and persistence, biometric technology can solve the problem of insurance fraud in life insurance and health insurance. If a facial recognition system can be installed in the pension payment system, after collection and entry work is completed, the insured can receive their pension with a "face sign in" at the corresponding time.

\subsubsection{Helps to Prevent and Mitigate Claims}

A super large amount of compensation, also known as an "abnormal value," often leads to a higher compensation ratio. Big data technology can help insurance companies find outliers in real-time and make effective interventions to curb the further development of outliers. For example, in health insurance, data analysis technology is used to automatically track and pay attention to the disease development process of an injured insured. Once the threshold is reached, follow-up treatment can be recommended in real-time, so as to avoid the development of more serious diseases.

Some insurance companies provide smart home technology for policyholders, which can help prevent and mitigate claims. For example, an insurance company can work with a security company to install smart home devices in the insured's homes. This set of intelligent equipment can automatically turn off the valve before water floods the home, eliminating a potential safety hazard; or inform the residents remotely to take measures to reduce a loss when a break-in or other property crime is occurring; or automatically adjust the light or temperature for people in need of home care, and provide a medical alarm service.

\section{THE CHALLENGES FACED BY INSURANCE COMPANIES}

\subsection{Conflicts}

Big data enables insurance companies to grasp market development trends and better understand the deep-seated needs of customers. The marketing process not only pursues current profits, but also promotes the transformation of customer resources and customer assets. In contrast, traditional insurance industry marketing still adheres to the old idea of starting from its own products to a large extent, and even ignores the actual needs of customers in order to pursue a high-premium scale. It can be said that this traditional marketing model has an obvious conflict with the data-based model advocated by the big data industry.

\subsection{Data Value}

The insurance industry is a data-intensive industry with fast a data accumulation speed. At present, the data accumulated by the insurance industry is mainly based on traditional business operation modes, which come from underwriting, payment, claims settlement, and other links. The customer information, payment records, and other information generated have great repeatability, which can be used as identity identification and account vouchers, but is insufficient to deeply understand the customers' personalized characteristics and specific needs. Although a large number of insurance claims information is recorded, it is often limited to an individual event, with strong contingency, lack of continuity, and regularity, and it is difficult to carry out deep risk internal cause mining. Compared with the requirements of the Internet for big data, existing data in the insurance industry are obviously insufficient in frequency, activity, real-time acquisition, and other aspects. If we refer to the definition standard of the " $4 \mathrm{~V}$ " of big data, the insurance data meets the requirements of large volume, but the update speed is slow, the structure is single, and the activity is insufficient, which cannot meet the requirements of variety and velocity, so the value is limited. The data analysis of the insurance industry is mainly limited in terms of structured data recording, and the application mining of unstructured data has yet to be started.

\subsection{Insufficient Interactions}

There are many reasons for the insufficient interaction between the insurance industry and customers' limited data sources: the format and homogeneity of insurance contracts and products and services are obvious, which limits the choices of customers and affects the interactions between the insurance company and its customers. Insurance company pricing is based on the principle of large numbers and focuses on group standardization, so it neglects the analysis and tracking of individual customers; some insurance company's official websites are too professional, making it difficult for customers to understand and causing asymmetry in information acquisition, which sets a low threshold for customer interaction.

\subsection{Data Island}

The foundation of big data applications is the data source. One of the keys to solve the data source issue is the opening and sharing of data. Otherwise, the big data market will be narrow and many innovations and applications will not be realized. There have been data islands in the insurance industry for a long time, which are mainly manifested in the following aspects. Data islands within one insurance company consist of different systems and departments having different conflicts of interest and concerns, which is reflected in the integrity and timeliness of information sharing. Data islands within the insurance industry consist of the fact that insurance is based on the principle of large numbers, so if data sharing between companies can be realized, it will greatly benefit their operation and management, but data sharing channels have not been fully opened between companies at present. Data islands between industries consist of, in addition to the vehicle insurance platform, the fact that there are not many successful cases of cross-industry data sharing in the insurance industry. Most companies only analyze and mine their existing business data, which greatly affects the depth and effect of the analysis. There is also a government and industry public data island, in that government public data mainly refers to the information produced by the government in the process of its 
administration, such as the information brought by administrative licensing, court proceedings, and other activities. Industry public data mainly refers to the data resources reported or shared by various insurance industry associations, alliance institutions, and other units. A large number of valuable data are held in government departments, neither shared nor open to companies. The data between these departments are not open and mobile, and a large number of information and statistics are idle, or even repeated.

\subsection{Cross-border Competition}

As a part of the big data industry supply chain, insurance companies will face more and more cross-border competition. For example, Internet companies or big data service platforms can establish Internet insurance companies through their own mature platforms and large audiences, or they can build an Internet-based insurance platform. On the one hand, this enhances their user stickiness and mastery of more user information; on the other hand, it blocks direct contact between insurance companies and customers, and enhances the dependence of insurance companies on customers.

\section{BIG DATA STRATEGIES OF INSURANCE COMPANIES}

One strategy is to find big data application mode that suits insurance companies. Insurance companies can use the following models for reference. First, with the help of big data, it may close the distance between customers, carry out the analysis of customers' personalized characteristics, improve the management and control of data analysis of businesses, and establish a new and more accurate risk management mode. The second strategy is to provide additional, personalized, value-added services by mining customer needs, which not only helps open up new business, but also improves the customer experience, improves customer loyalty, and promotes the transformation of customer resources and customer assets. The third strategy is to find a profit model suitable for insurance companies. Most small- and medium-sized insurance companies are limited by their technical strengths, customer resources, and other factors. They can only rely on their own condition; therefore making it difficult for them to establish a mature big data platform in a short period of time. For insurance companies, trying to cooperate with Internet e-commerce platform, Internet of Things, electronic maps, and other industries is not an option. Cooperation includes the purchase of technology, as well as establishment of a business cooperation mode, taking advantage of other platforms and resources and promoting the company's gradual successful transformation from a product-driven mode to a data-driven mode.

Secondly, expand data acquisition channels with the help of Internet and mobile terminals. Data is the source of big data applications. The insurance industry should change from relying on traditional human means (such as a marketing team) to accumulate data. Insurance companies should try to transcend the limitations of traditional data collection modes, with the help of the rapid development of Internet and mobile terminals, take the network as a bridge, expand data channels, and capture high frequency personalized data of customers. First, through the company website, WeChat public number and other media, insurance companies enhance their interactions with customers. Based on the customer perspective, professional insurance clauses are expressed in popular forms of interest, such as video, animation, etc. The second is to emphasize customer participation, open columns on the website and WeChat, design elements of the insurance contract into different modules, allow customers to combine different modules freely, form the insurance products they need to their specification, so that customers are not only consumers, but also product designers, thereby enabling the insurance company to really understand market and customer needs, so as to provide future product innovation. Third, strengthen the cooperation with the Internet and e-commerce platforms. Insurance companies should participate in network business services; establish a communication bridge with customers with the help of e-commerce platforms, obtain customers' activity information on the network, expand data sources, and provide bases for big data applications.

The third is to adjust the company structure and build a business-driven organizational model. The traditional "pyramid" hierarchical structure of insurance companies has many levels of management, leading to negative qualities such as slow information transmission, poor accuracy, and insensitivity to market changes, low operating efficiency, and the inability to meet the requirements of big data. Under the auspices of big data, because core analysis ability and the technology of big data have outstanding synergy among business departments, the setting of big data organization goals should not be technology driven, but business driven. The authority related to business decision-making should be granted to front-line departments to ensure the seamless connection between data analysis and decision-making.

The fourth is infrastructure construction and investment. In order to improve the infrastructure for big data, insurance companies need to integrate the company's original internal and external data resources, build a basic information system, build a data warehouse and data mart, build a software and hardware environment for big data research and analysis, establish a database of big data analysis methods, and develop and purchase big data analysis software tools. In order to play the role of big data software and hardware infrastructure, insurance companies need to establish a series of data management supporting mechanisms to maintain and update the database and data management information systems, and these measures need huge investment.

The fifth is to explore the application of new big data technologies. Big data depends on the support and innovation of technology with the rapid development of the Internet, distributed computing, unstructured data analysis, and many other technologies. If the insurance industry wants to establish its own big data use, it must pay more attention to the exploration and application of new technologies. The following technologies are feasible. One is an IoT-based technology, of which the smart grid is a successful example. Smart meters are used as data terminals to collect data from both sides of supply and demand. Through analysis, decisions are made, key performance indicators are improved, and digital driving is realized. The industry can 
use the automobile insurance business as the entry point, cooperate with electronic map suppliers and other industries, establish an Internet of vehicles, turn insured vehicles into mobile data sources, and obtain customer information in real time. Insurance companies should also use unstructured data analysis technology. Unstructured data accounts for the majority of insurance company's data, and may contain a large amount of information. If it is not fully utilized, it not only greatly limits the amount of data, but also limits the data analysis to a binary relational database mode.

Sixth, establish a big data talent team. Big data construction can not only rely on its technicians, but also needs the participation of data scientists, business backbones, sales elites, investment experts, and other diversified talents. Internet companies and e-commerce companies that have made great success in the application of big data rely on teams with a variety of talents. This lesson is worth learning for the insurance industry. Some large insurance companies have set up special big data departments and organized big data teams with all kinds of professionals. Insurance companies should realize that big data is not only the responsibility of IT departments, but companies must find their own directions and goal in big data applications, and gradually build a diversified talent team, so as to find opportunities in the big data wave.

\section{ACKNOWLEDGMENT}

This article is funded by grants from National Science Foundation of China (71903209), and Basic Scientific Research Business Expenses of Central University (QL18008).

\section{REFERENCES}

[1] Agarwal, R., and Dhar, V., Big Data, Data Science, and Analytics: The Opportunity and Challenge for IS Research, Information Systems Research (25:3), 2014(9): 443-448.

[2] Agarwal, S., and Hauswald, R., Distance and Private Information in Lending, Review of Financial Studies (23:7), 2010(7):2757-2788.

[3] Akerlof,G., The Market for Lemons,Quarterly Journal of Economics (84), 1970:488-500.

[4] Barron, J. M., and Staten, M. , The value of comprehensive credit reports: Lessons from the US experience, Credit Reporting Systems and the International Economy, 2003: 273-310.

[5] Belanger, F., and Crossler, R. E., Privacy in the Digital Age: A Review of Information Privacy Research in Information Systems, MIS Quarterly (35:4), 2011(10): 1017-1041.

[6] Birchler, U., and Butler, M. Information Economics, 2007. Brown, M., Jappelli, T., and Pagano, M., Information sharing and credit: Firm-level evidence from transition countries, Journal of Financial Intermediation (18:2), 2009(4): 151-172.

[7] Brown, M., and Zehnder, C., Credit reporting, relationship banking, and loan repayment, Journal of Money Credit and Banking (39:8), 2007(12):1883-1918.

[8] Chandler, G. G. R. W. J., The Benefit to Consumers From Generic Scoring Models Based on Credit Reports,
IMA Journal of Mathematics Applied in Business and Industry, 1992(4): 61-72.

[9] Davenport, T. H., Competing on analytics, Harvard Business Review (84:1), 2006(1):98-+.

[10] Djankov, S., McLiesh, C., and Shleifer, A., Private credit in 129 countries, Journal of Financial Economics (84:2), 2007(5):299-329.

[11] Goes, P. B., Big Data and IS Research, MIS Quarterly (38:3), 2014(9): Iii-Viii.

[12] Hauswald, R., and Marquez, R., Competition and strategic information acquisition in credit markets, Review of Financial Studies (19:3), 2006(2):967-1000.

[13] Jappelli, T., and Pagano, M., Information sharing, lending and defaults: Cross-country evidence, Journal of Banking \& Finance (26:10), 2002: 2017-2045.

[14] Kallberg, J. G., and Udell, G. F., The value of private sector business credit information sharing: The US case, Journal of Banking \& Finance (27:3), 2003(3):449-469.

[15] Klein, D. B., Promise Keeping in the Great Society: A Model of Credit Information Sharing, Economics and Politics (4:2), 1992:117-136.

[16] Kohli, R., and Grover, V., Business value of IT: An essay on expanding research directions to keep up with the times, Journal of the Association for Information Systems (9:1), 2008: 23-39.

[17] Lin, Z., Whinston, A. B., and Fan, S., Harnessing Internet finance with innovative cyber credit management, Financial Innovation (1), 2015:5.

[18] Luoto, J., Mcintosh, C., and Wydick, B., Credit information systems in less developed countries: A test with microfinance in Guatemala, Economic Development and Cultural Change (55:2), 2007(1):313-334.

[19] McIntosh, C., and Wydick, B., Competition and microfinance, Journal of Development Economics (78:2), 2005:271-298.

[20] Padilla, A. J., and Pagano, M., Sharing default information as a borrower discipline device, European Economic Review (44:10), 2000:1951-1980.

[21] Pagano, M., and Jappelli, T., Information Sharing in Credit Markets, Journal of Finance (48:5), 1993:1693-1718

[21] Stigler, J., Economics of Information, Journal of Political Economics (69), 1961:213-225.

[22] Stiglitz, J. E., and Weiss, A., Credit Rationing in Markets with Imperfect Information, American Economic Review (71:3), 1981:393-410.

[23] Vercammen, J. A., Credit Bureau Policy and Sustainable Reputation Effects in Credit Markets, Economica (62:248), 1995:461-478.

[24] Wang, G. A., Atabakhsh, H., and Chen, H. C., A hierarchical Naive Bayes model for approximate identity matching, Decision Support Systems (51:3), 2011(6): 413-423.

[25] Yu, L., Li, X., Tang, L., Zhang, Z., and Kou, G., Social credit: a comprehensive literature review, Financial Innovation (1), 2015:6 